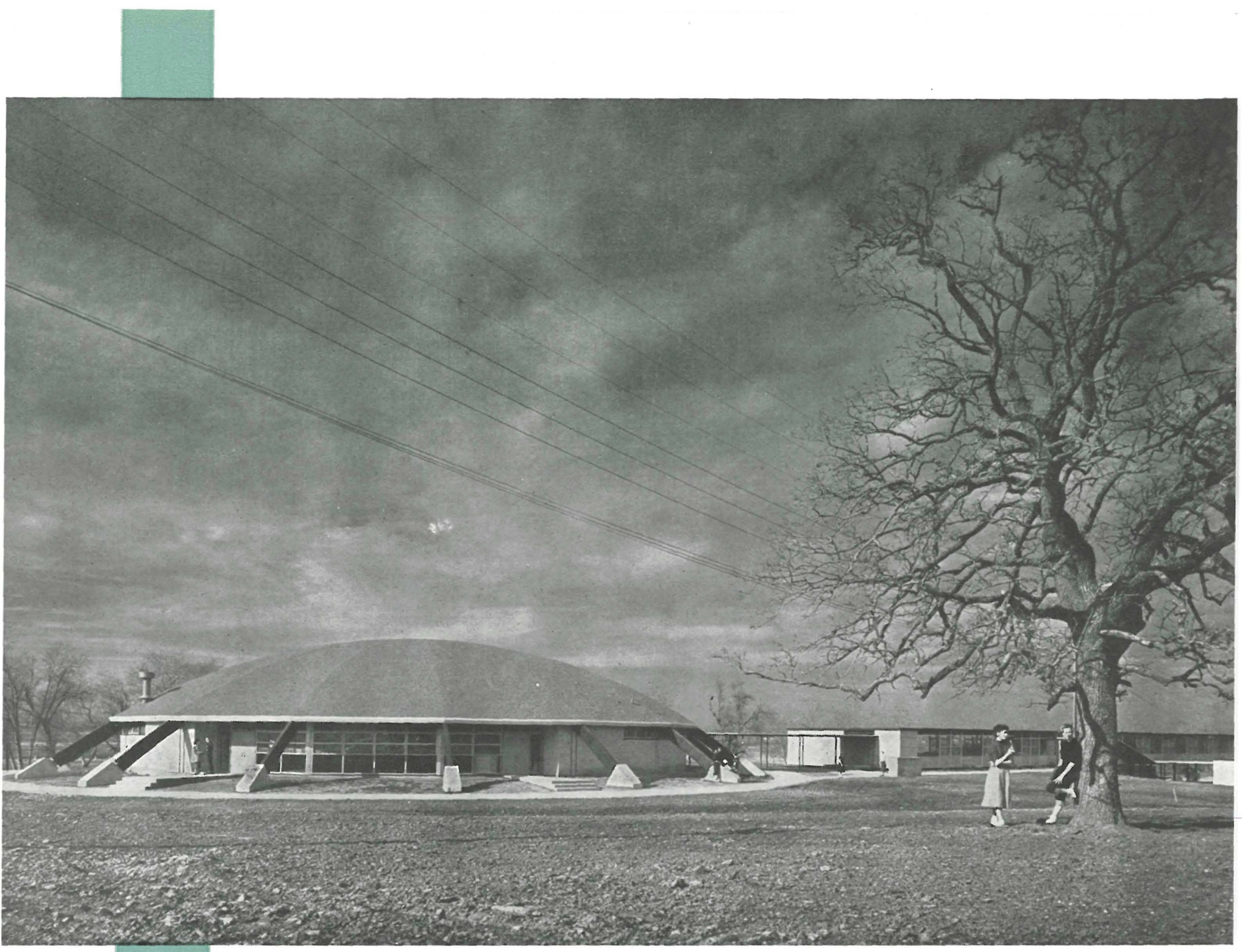

$141-42$

\section{escuela secundaria, en Tejas}

Arquitectos: CAUDILL, ROWLETT, SCOTT \& Associates Brazos Chapter

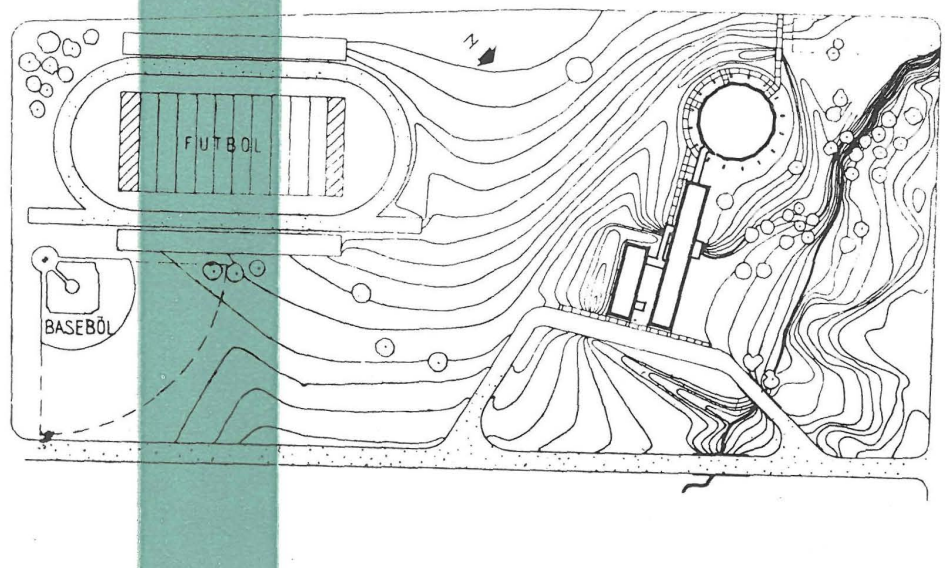

El problema que planteaba este proyecto consistía en proveer de una escuela digna a una pequeña comunidad que crece rápidamente, con los cambios de cualquier aspecto que esta circunstancia trae consigo y con gran limitación en el presupuesto disponible

La solución adoptada es, sin duda, económica; y la fisonomía estética del resultado, satisfactoria: simplificacion de líneas y una distribución racional dentro del funcionalismo adecuado.

El terreno presenta una pendiente ligeramente acusada alrededor del auditorio, desde el que se accede a los dos bloques escolares, que tienen orientación NE.-SO. Estos dos pabellones paralelos tienen diferente altura-dos plantas el mayor y una el más reducido-, lo que proporciona gracia y movilidad al conjunto, a la vez que las plantas rectangulares de los edifilas plantas rectangulares de los edificios destinados a clases contrastan y
armonizan con la circular del auditorio. 


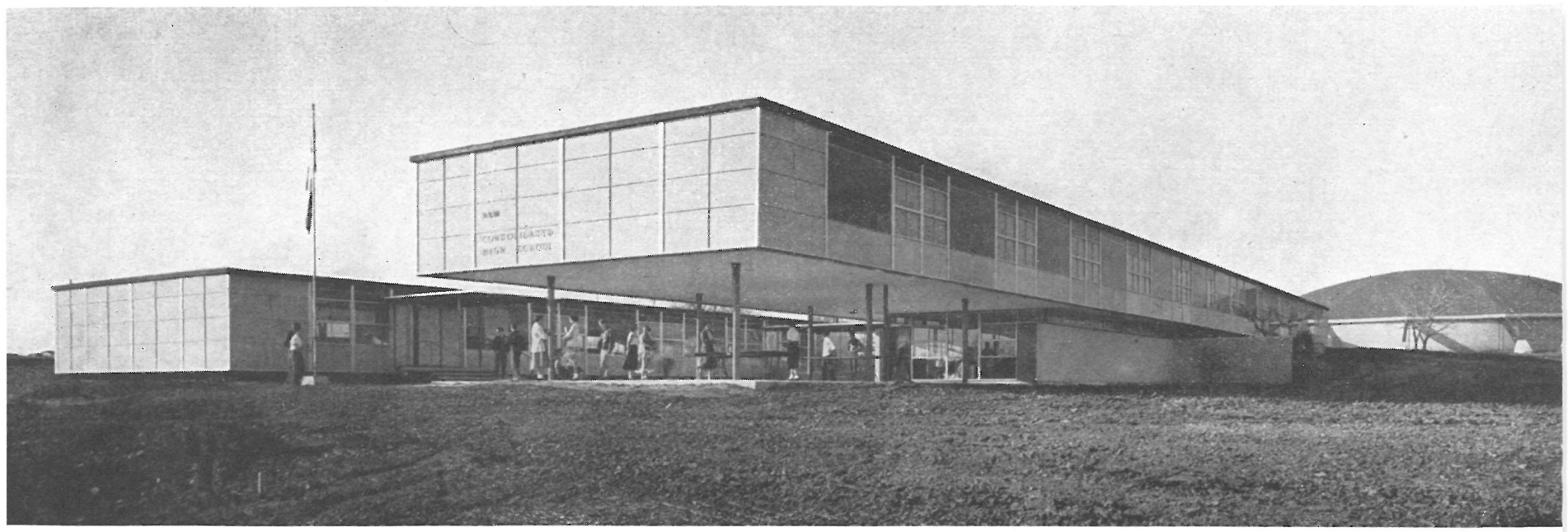

Se prevé una capacidad de 210 alumnos.

Los materiales empleados son: cimentación de pilotes de hormigón; soportes y vigas de acero; viguetas de madera; cerramientos de ladrillo hueco de color amarillento; asbestocemento y cristal; paneles de tabiquería en corcho, yeso madera laminada; lucernarios de plástico; pavimentos de losetas de as falto (sobre losa de hormigón, y acabado de cubiertas con grava y alquitrán.

Las clases se disponen en línea, a lo largo de bloque más grande, dejando abierta la parte que comunica con el pasillo, que, en realidad, no presenta carácter de tal. A continuación está tal. A continuación está te un salón de actividades varias. El espacio debajo de las clases, se ha dejado sin cerrar para utilizarlo como cubierto.

El bloque pequeño con tiene salas de ciencia arte, negocios y labore del hogar.

Completan el programa, además del auditorio, campos de fútbol y base-bool, situados muy cerca de las construcciones.

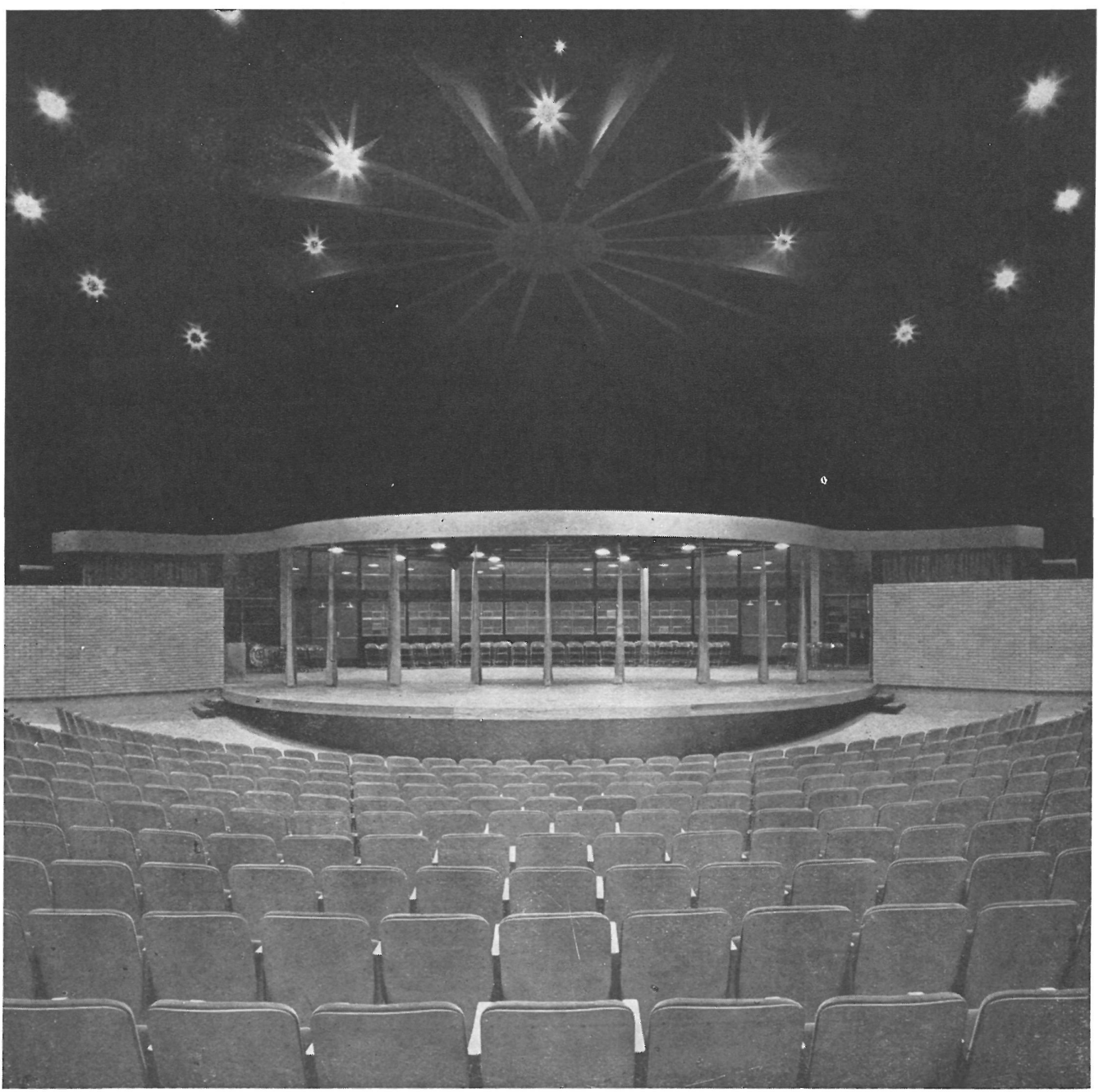




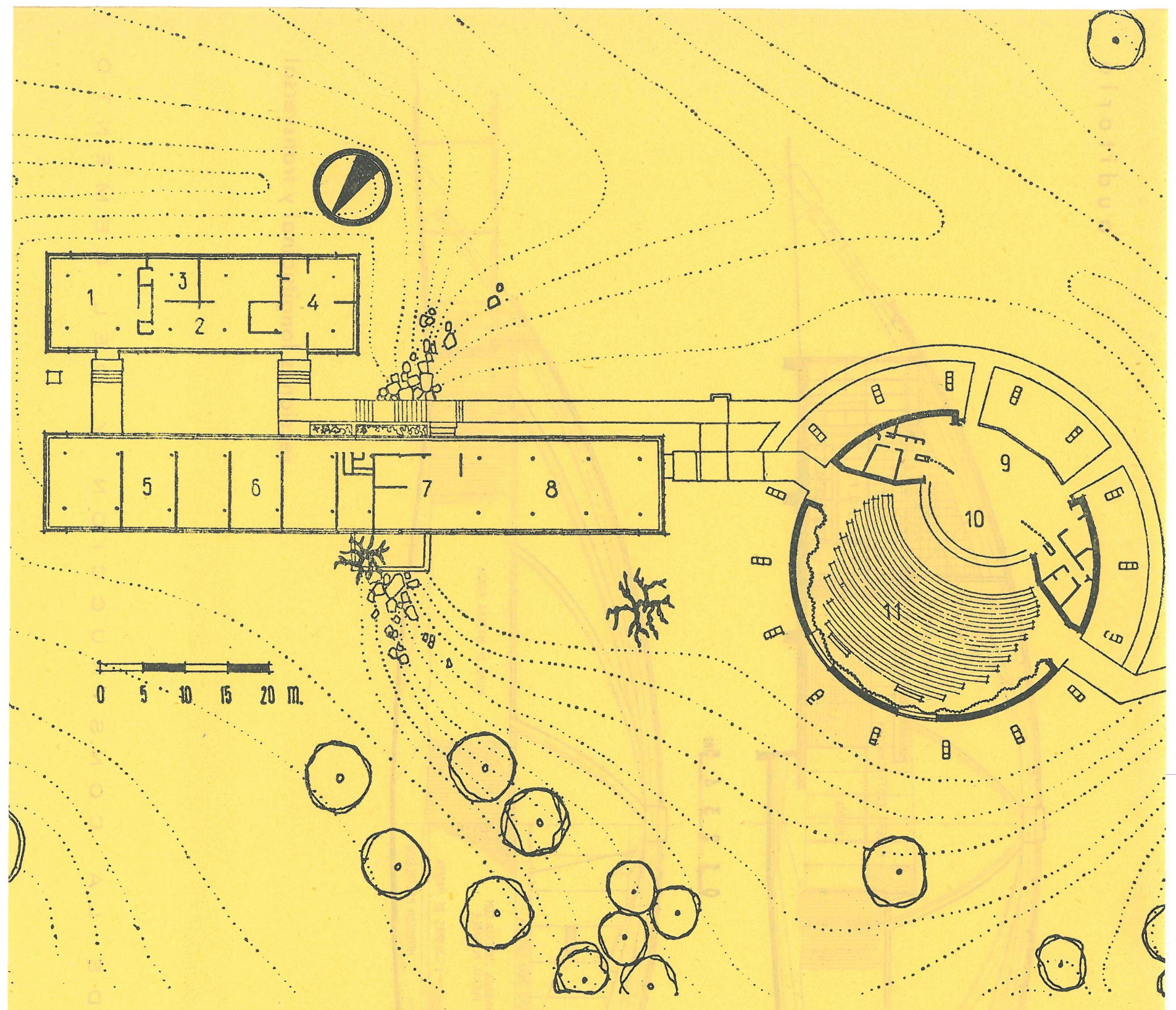

El auditorio, en forma de un casquete, está formado por arcos resistentes de madera laminada vista. Como es lógico, el auditorio, que está situado en la parte más alta del terreno, es la pieza ornamental y más vistosa del conjunto.

Todo aquí está presidido por una norma básica: economí. No obstante, la solución es elegante y esbelta, ligera y diáfana. La distribución interior es muy agradable, y consigue una impresión de independencia e individualidad de cada clase, sin cerrar los recintos por completo, con lo cual se obtiene el efecto de una gran libertad y mayor amplitud.

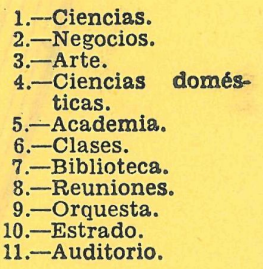

planta 
0
0
0
\pm
$=0$
0
0
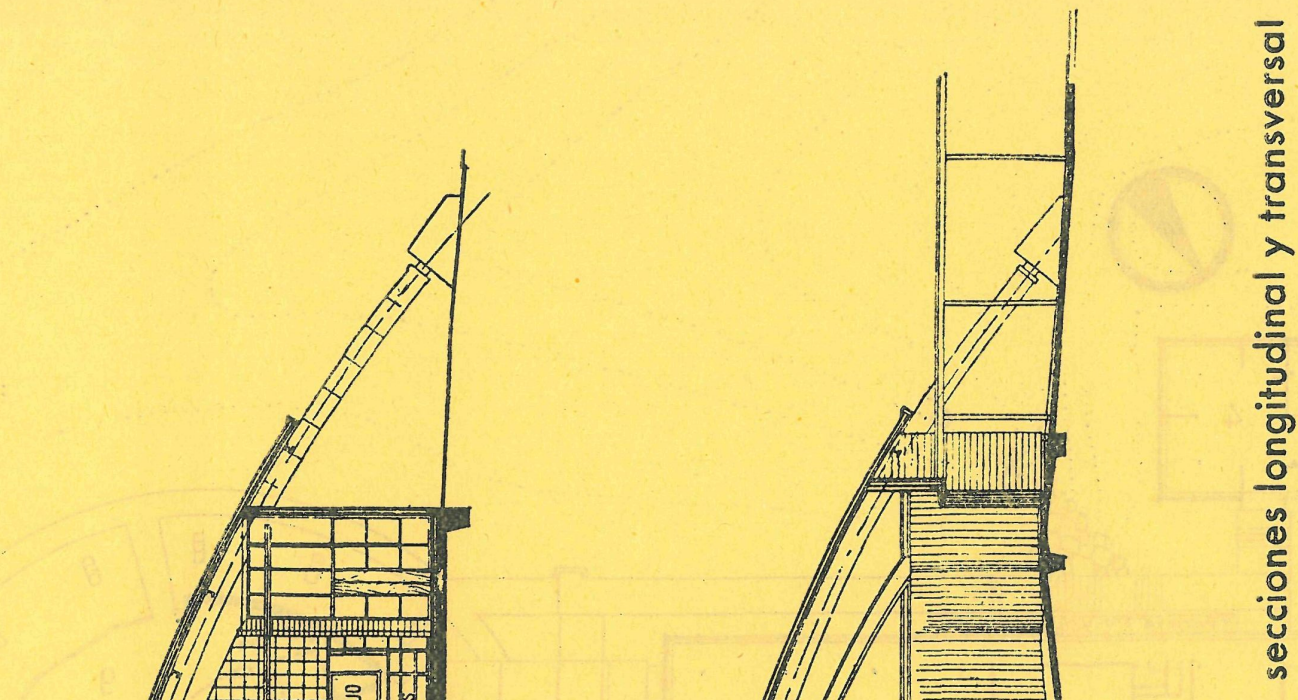

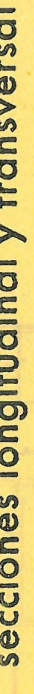
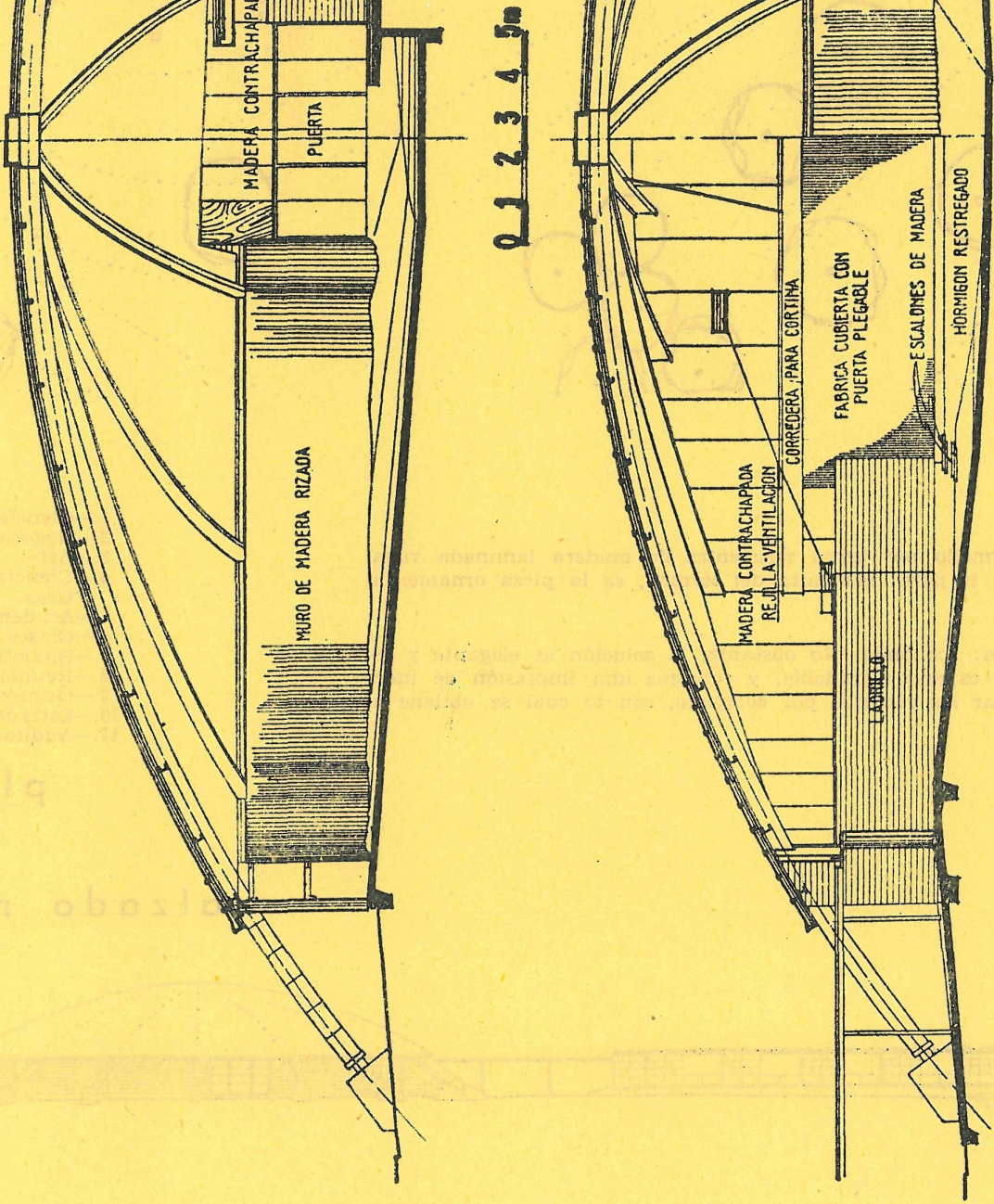


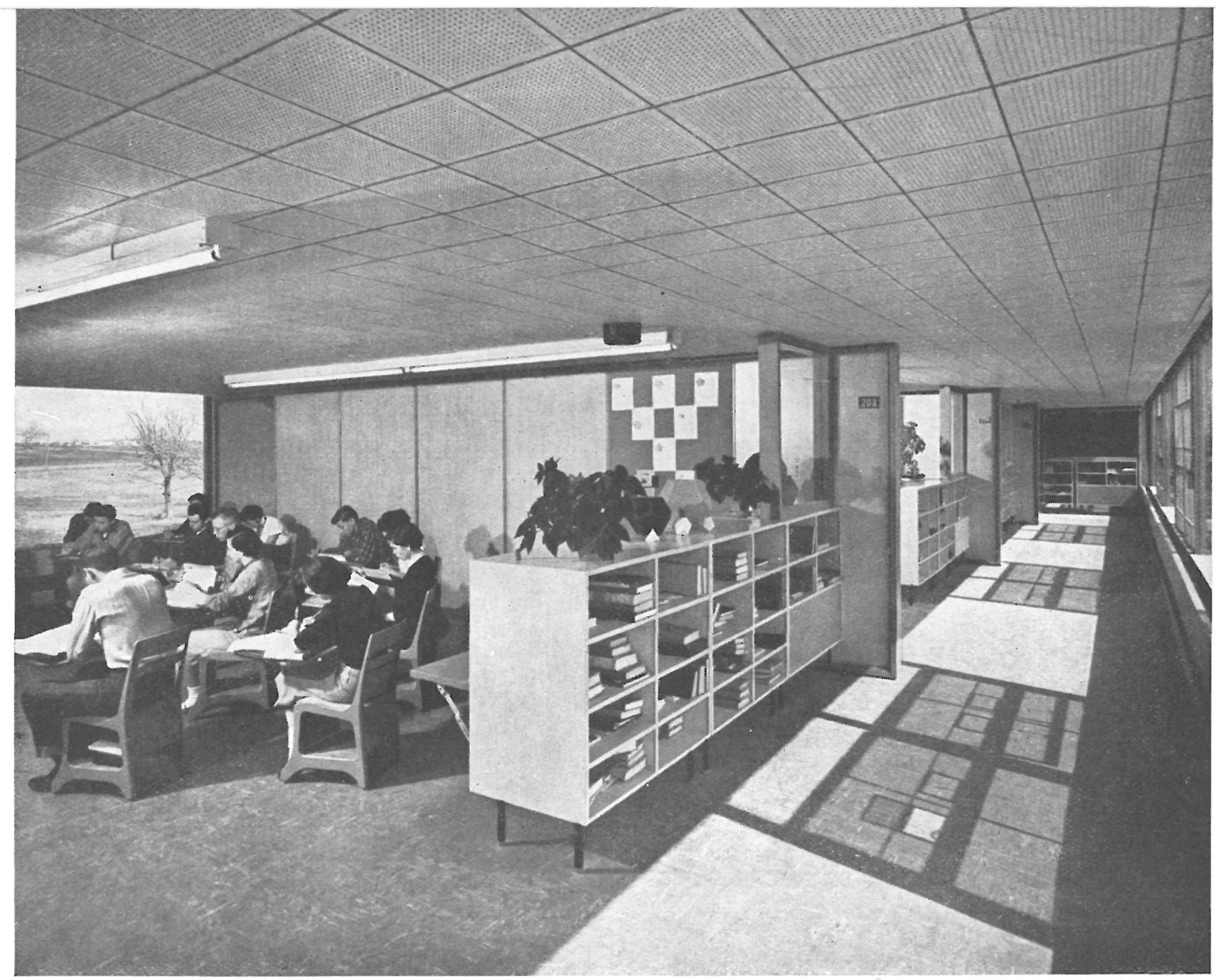

clases

clases 